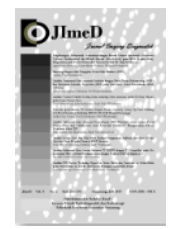

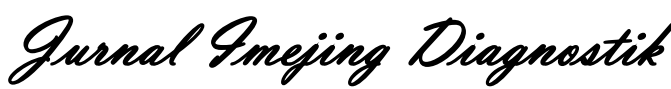

e-ISSN 2621-7457, p-ISSN 2356-301X

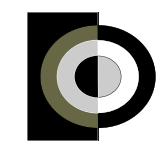

http://ejournal.poltekkessmg.ac.id/ojs/index.php/iimed/index

\title{
Perbedaan Informasi Anatomi Pada Ct Scan Abdomen Antara Penggunaan Protokol Sure Exposure Dan Tanpa Sure Exposure
}

\author{
Devita Rizkania Indarsari ${ }^{1)}$, Jeffri Ardiyanto ${ }^{1)}$, Andrey Nino Kurniawan ${ }^{1)}$ \\ 1) Jurusan Teknik Radiodiagnostik dan Radioterapi Poltekkes Kemenkes Semarang, Indonesia \\ e-mail: devitarizkania10@gmail.com
}

Received: Mei 31 ${ }^{\text {th }}, 2019$; Revised: June 30 ${ }^{\text {th }}, 2019$; Accepted: July 09 ${ }^{\text {th }}, 2019$

\begin{abstract}
Background: Image quality Abdomen CT scan indicated by low noise or image noise values within acceptable standard limits. On CT Scan there is an auto mAs called Sure exposure to ensure constant image quality at the lowest possible dose. The purpose of this study was to determine the difference of anatomical information of sure exposure protocol and without sure exposure on CT scan of Abdomen also to know better protocols in producing quality on CT Scan Abdomen between usage protocol sure exposure and without sure exposure.

Method: This research is a kind of quantitative research with an experimental approach. This study used the CT Scan Multislice 128. CT scan of Abdomen with use sure exposure protocol and without sure exposure. The results were obtained based on respondents assessment through Liver, Spleen, Adrenal Gland, Kidney, Pancreas and Abdominal Wall. Analyze this research data using statistical test normality data and Mann Whitney test.

Result: The results of the questionnaires of respondents showed no significant difference. The value of Mann Whitney's overall significance of the abdominal anatomy is 0.549 ( $\mathrm{p}$ value $>0.05$ ). Protocol Sure Exposure is better on the organ of adrenal glands, kidneys, and pancreas, whereas protocols without sure exposure are better in liver, spleen, kidney, pancreas, and abdominal wall. The use of protocols without sure exposure better in generating information.

Conclusion: In general the protocol of sure exposure and without sure exposure has the same clarity of anatomical information. But the protocol without a sure exposure has more information than the sure exposure protocol.
\end{abstract}

Keyword: Anatomical Information of Abdominal; CT Scan Abdomen; Protocol Sure Exposure; Protocol Without Sure Exposure

\section{Pendahuluan}

CT Scan merupakan peralatan diagnostik yang sangat diperlukan dalam pelayanan radiologi (Karthikeyen, 2005). Computed tomography (CT) adalah modalitas radiologi untuk mengevaluasi berbagai kelainan, meskipun tidak semua kelainan dapat dideteksi menggunakan CT Scan. Namun CT Scan hanya dapat dilakukan dengan alasan medis yang benar dan dengan dosis radiasi minimum.

Salah satu pemanfaatan CT Scan adalah untuk pemeriksaan abdomen. CT Scan abdomen dapat memberikan diagnosis patologis yang cepat dan efektif. Untuk itu, permintaan CT Scan Abdomen belakangan ini meningkat secara drastis.

CT Scan abdomen membutuhkan faktor eksposi yang besar. Faktor eksposi yang diberikanpun berbeda-beda sesuai dengan ukuran pasien. Untuk itu pengaturan protokol secara manual memerlukan operator CT Scan yang berpengalaman untuk menghasilkan kualitas citra yang maksimal.
Kualitas citra CT Scan abdomen dikatakan baik ditunjukkan dengan rendahnya noise atau nilai image noise dalam batas standar yang bisa diterima. Tingginya nilai noise akan menghasilkan resolusi kontras yang rendah sehingga informasi anatomi yang didapatkanpun tidak maksimal.

Begitu pula sebaliknya apabila nilai noise rendah akan menghasilkan resolusi kontras yang tinggi sehingga informasi anatomi yang didapatkanpun akan lebih baik (Seeram, 2009).

Salah satu penggunaan parameter yang mempengaruhi image noise adalah mAs. Apabila nilai $\mathrm{mAs}$ semakin tinggi maka noise akan semakin rendah sedangkan nilai mAs semakin rendah maka noise yang dihasilkan akan semakin tinggi pada gambaran CT Scan. Menurut Resmana (2017), pada aplikasi lain yang serupa dengan sure exposure menjelaskan bahwa menggunakan aplikasi care dose (auto mAs) dapat menurunkan nilai image noise dibanding dengan tidak menggunakan aplikasi care dose. 
Pada pesawat CT Scan Toshiba terdapat fasilitas software pengaturan auto mAs, yang disebut dengan Sure Exposure. Sure Exposure/auto $m A s$ merupakan sebuah sistem yang terdapat dalam automatic exposure control (AEC), untuk memastikan kualitas gambar diagnostik yang konstan atas seluruh bagian-bagian tubuh karena dengan dosis serendah mungkin. Dosis radiasi dengan mengubah mAs berdasarkan ukuran tubuh pasien dan atenuasi secara otomatis. Software ini dapat mengurangi dosis radiasi hingga $40 \%$ sampai $50 \%$.

Mengingat berpengaruhnya nilai mAs pada penggunaan Sure Exposure terhadap image noise sebagai salah satu komponen kualitas citra radiograf, seorang radiografer harus memiliki pengetahuan mendalam mengenai aplikasi Sure Exposure. Kinerja alat juga harus diperhatikan sehingga keluaran mAs sesuai dengan yang diatur. Hal ini disebabkan karena perubahan keluaran mAs berpengaruh terhadap noise yang dapat mengurangi kualitas gambar. Kualitas gambar yang kurang optimal akibat adanya noise, dapat membuat radiolog menjadi kesulitan dalam menegakkan diagnosa. Hal ini juga dapat menyebabkan kesalahan dalam menegakkan diagnosa. Oleh karena itu, kedua hal tersebut harus senantiasa diperhatikan untuk menjaga kualitas gambar dengan mempertahankan nilai dosis sekecil-kecilnya.

\section{Metode}

Penelitian ini adalah penelitian kuantitatif dengan pendekatan eksperimen untuk mengetahui perbedaan informasi anatomi pada penggunaan protokol sure exposure dan tanpa sure exposure pada pemeriksaan CT Scan Abdomen.

Sampel yang digunakan adalah pasien pemeriksaan CT Scan Abdomen dewasa di Instalasi Radiologi RSSA Malang. Diambil 10 sampel untuk dilakukan pemeriksaan dengan menggunakan protokol sure exposure dan 10 sampel untuk dilakukan pemeriksaan tanpa menggunakan protokol sure exposure.

20 sampel dilakukan pemeriksaan CT Scan Abdomen sesuai dengan SOP yang berlaku di RSSA Malang. 10 sampel dilakukan pemeriksaan dengan menggunakan protokol sure exposure atau auto mAs dan 10 sampel lainnya dilakukan pemeriksaan tanpa menggunakan protokol sure exposure yaitu dengan protokol abdomen 300 mAs.

Data yang terkumpul dievaluasi informasi anatomi pada enam anatomi citra yaitu liver, spleen, adrenal gland, kidney, pancreas, dan abdominal wall.

Data yang terkumpul diolah dengan pengolahan data deskriptif. Untuk mengetahui tingkat persamaan antar responden dilakukan dengan Uji Cohen's Kappa. Apabila Kappa value berada pada rentang 0.6-0.8 maka tingkat persamaan persepsi dinyatakan hampir sempurna.

Hasil pengujian dokter spesialis radiolog dilakukan Uji Cohen's Kappa untuk mengetahui tingkat obyektifitas dari penilaian responden terhadap pemakaian protokol sure exposure dan tanpa sure exposure. Selanjutnya data dianalisa dengan uji tabulasi silang untuk menentukan persentase penilaian kejelasan informasi anatomi citra dari responden. Kemudian dilakukan uji Mann Whitney U Test untuk mengetahui perbedaan kejelasan informasi anatomi terhadap kedua protokol tersebut, jika $p$-value lebih kecil atau sama dengan 0.05 maka Ha diterima dan Ho ditolak.

\section{Hasil dan Pembahasan}

Pada pemeriksaan CT Scan Abdomen, 10 sample dilakukan pemeriksaan dengan menggunakan protokol sure exposure dan 10 sample dilakukan pemeriksaan dengan menggunakan protokol tanpa sure exposure. Pada penelitian ini pengaturan protokol divariasikan dengan menggunakan protokol abdomen sebagai protokol sure exposure dan protokol abdomen 300 mAs sebagai protokol tanpa sure exposure.

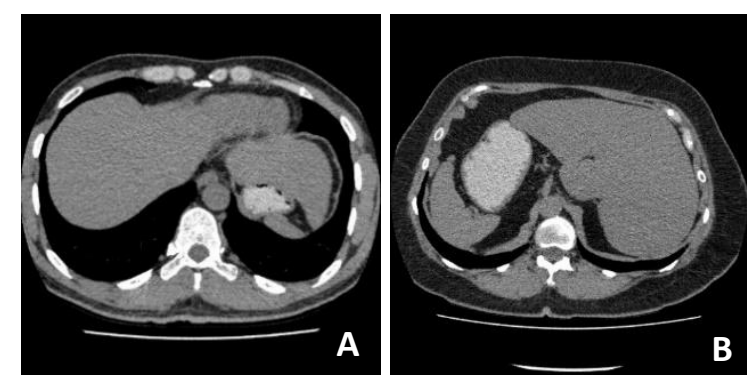

Gambar 1. Hasil Citra CT Scan Abdomen Protokol Sure Exposure (A) dan Tanpa Sure Exposure (B)

Hasil citra masing-masing sample kemudian dianalisis oleh responden, yaitu 3 orang dokter spesialis radiologi. Analisis dilakukan berdasarkan kejelasan informasi anatomi organ abdomen meliputi Liver, Spleen, Adrenal Gland, Kidney, Pancreas dan Abdominal Gland. Responden melakukan checklist $(\sqrt{ })$ pada lembar kuesioner yang telah disediakan. Penilaian terhadap kejelasan informasi anatomi dilakukan dengan memberi nilai 
(skor) dengan rentang 1 (minimal) sampai 3 (maksimal).

Data yang diperoleh dari hasil kuesioner dianalisis terlebih dahulu tingkat kesepakatan (Degree of Agreement) antara ketiga responden dengan menggunakan uji Cohen's Kappa.

Berdasarkan hasil uji kappa menunjukkan bahwa kesepakatan antara responden 2 dan responden 3 yang mempunyai reliabilitas baik dengan kappa value 0.783. Menurut Altman (1991), nilai koefisien kappa <0.2 menunjukkan tingkat kesepakatan buruk (poor), nilai koefisien kappa antara 0.21 sampai 0.60 menunjukkan tingkat kesepakatan sedang (moderate), nilai koefisien kappa antara 0.61 sampai 0.80 menunjukkan tingkat kesepakatan baik (good), dan nilai koefisien antara $0.81-1.00$ menunjukkan tingkat kesepakatan sangat baik (very good). Sehingga data yang peneliti gunakan adalah data informasi citra dari reviewer ketiga, dikarenakan reviewer ketiga merupakan dokter radiolog konsulen sehingga dinilai lebih berpengalaman.

Tabel 1. Rekap Hasil Kuesioner

\begin{tabular}{lcccccc}
\hline \multirow{2}{*}{$\begin{array}{l}\text { HASIL } \\
\text { CITRA }\end{array}$} & \multicolumn{2}{c}{ LIVER } & \multicolumn{2}{c}{ SPLEEN } & \multicolumn{2}{c}{ ADRENAL } \\
\cline { 2 - 7 } & SE & TSE & SE & TSE & SE & TSE \\
\hline CITRA 1 & 7 & 7 & 6 & 8 & 7 & 6 \\
CITRA 2 & 8 & 7 & 9 & 7 & 7 & 7 \\
CITRA 3 & 7 & 8 & 8 & 9 & 7 & 7 \\
CITRA 4 & 8 & 9 & 7 & 8 & 7 & 6 \\
CITRA 5 & 6 & 7 & 7 & 7 & 8 & 8 \\
CITRA 6 & 8 & 7 & 9 & 7 & 6 & 7 \\
CITRA 7 & 6 & 7 & 7 & 7 & 7 & 7 \\
CITRA 8 & 9 & 8 & 7 & 8 & 7 & 8 \\
CITRA 9 & 8 & 8 & 9 & 7 & 8 & 8 \\
CITRA 10 & 6 & 8 & 6 & 7 & 8 & 6 \\
TOTAL & 73 & 76 & 75 & 76 & 72 & 70 \\
RERATA & 2.4 & 2.5 & 2.5 & 2.5 & 2.4 & 2.3 \\
\hline
\end{tabular}

Tabel 2. Rekap Hasil Kuesioner

\begin{tabular}{lcccccc}
\hline \multirow{2}{*}{ HASIL } & \multicolumn{2}{c}{ KIDNEY } & \multicolumn{2}{c}{ PANCREA } & \multicolumn{2}{c}{ ABDOMIN } \\
CITRA & SE & TSE & SE & TSE & AL WE & TSE \\
\hline CITRA 1 & 8 & 8 & 7 & 7 & 8 & 9 \\
CITRA 2 & 9 & 8 & 7 & 8 & 7 & 8 \\
CITRA 3 & 9 & 9 & 6 & 8 & 8 & 7 \\
CITRA 4 & 8 & 8 & 8 & 7 & 7 & 8 \\
CITRA 5 & 8 & 8 & 7 & 6 & 8 & 8 \\
CITRA 6 & 8 & 9 & 7 & 7 & 8 & 8 \\
CITRA 7 & 7 & 8 & 8 & 7 & 8 & 7 \\
CITRA 8 & 7 & 8 & 7 & 8 & 9 & 7 \\
CITRA 9 & 7 & 7 & 8 & 8 & 7 & 7 \\
CITRA 10 & 8 & 7 & 7 & 7 & 7 & 8 \\
TOTAL & 79 & 79 & 73 & 73 & 77 & 78 \\
RERATA & 2.6 & 2.6 & 2.4 & 2.4 & 2.5 & 2.6 \\
\hline
\end{tabular}

Analisis secara bivariat menjelaskan tentang hubungan atau perbedaan satu variabel independen terhadap satu variabel dependen. Metode yang digunakan dalam penelitian ini adalah uji $\mathrm{T}$ tidak berpasangan (Paired sample $T$ ). Uji $\mathrm{T}$ tidak berpasangan dilakukan untuk melihat ada tidaknya perbedaan diantara dua kelompok yang tidak berpasangan, dengan syarat data berdistribusi normal ( $p>0.05)$. Jika tidak memenuhi syarat, maka dipilih uji alternatinya yaitu uji Mann Whitney.

Tabel 3. Hasil Uji Normalitas Data dengan Shapiro Wilk

\begin{tabular}{ccc}
\hline \multirow{2}{*}{ Area } & \multicolumn{2}{c}{ Sig } \\
\cline { 2 - 3 } & $\begin{array}{c}\text { Sure } \\
\text { Exposure }\end{array}$ & $\begin{array}{c}\text { Tanpa Sure } \\
\text { Exposure }\end{array}$ \\
\hline Liver & $<0.000$ & $<0.000$ \\
Spleen & $<0.000$ & $<0.000$ \\
Adrenal Gland & $<0.000$ & $<0.000$ \\
Kidney & $<0.000$ & $<0.000$ \\
Pancreas & $<0.000$ & $<0.000$ \\
Abdominal Wall & $<0.000$ & $<0.000$ \\
\hline
\end{tabular}

Berdasarkan tabel 3, diperoleh hasil normalitas data dengan nilai signifikansi untuk kedua kelompok data adalah $<0.001(\mathrm{p}<0.05)$. Artinya, distribusi kedua kelompok data adalah tidak normal, maka dipilih uji Mann Whitney sebagai alternatif uji T tidak berpasangan. Hasil uji Mann Whitney dapat dilihat pada tabel 4.

Tabel 4. Hasil Analisis Uji Mann Whitney tentang Informasi Anatomi

\begin{tabular}{|c|c|c|}
\hline Area Anatomi & Protokol & P Value \\
\hline Liver & $\begin{array}{l}\text { Sure exposure } \\
\text { dan Tanpa Sure } \\
\text { exposure }\end{array}$ & 0.280 \\
\hline Spleen & $\begin{array}{l}\text { Sure exposure } \\
\text { dan Tanpa Sure } \\
\text { exposure }\end{array}$ & 0.481 \\
\hline Adrenal gland & $\begin{array}{l}\text { Sure exposure } \\
\text { dan Tanpa Sure } \\
\text { exposure }\end{array}$ & 0.481 \\
\hline Kidney & $\begin{array}{l}\text { Sure exposure } \\
\text { dan Tanpa Sure } \\
\text { exposure }\end{array}$ & 1.000 \\
\hline Pancreas & $\begin{array}{l}\text { Sure exposure } \\
\text { dan Tanpa Sure } \\
\text { exposure }\end{array}$ & 1.000 \\
\hline Abdominal wall & $\begin{array}{l}\text { Sure exposure } \\
\text { dan Tanpa Sure } \\
\text { exposure }\end{array}$ & 0.280 \\
\hline
\end{tabular}

Berdasarkan hasil uji statistik non parametrik Mann Whitney pada tabel 4 menyatakan bahwa 
tidak adanya perbedaan signifikan antara penggunaan protokol sure exposure dan tanpa sure exposure terhadap informasi anatomi Liver, Spleen, Adrenal gland, Pancreas dan Abdominal wall dengan nilai signifikan masing-masing area $(\mathrm{p}>0.05)$.

\section{Protokol Yang Optimal}

Untuk mengetahui protokol yang lebih baik dalam mevisualisasikan informasi anatomi padd. pemeriksaan CT Scan Abdomen dengan penggunaan protokol sure exposure dan tanpa sure exposure, maka dapat dilihat pada tabel 5.

Tabel 5. Hasil Mean Rank Pada Uji Mann Whitney

\begin{tabular}{|c|c|c|}
\hline \multirow{3}{*}{ Area Anatomi } & \multicolumn{2}{|c|}{ Mean Rank } \\
\hline & Sure & Tanpa Sure \\
\hline & Exposure & Exposure \\
\hline Liver & 9.50 & 12.00 \\
\hline Spleen & 9.50 & 11.50 \\
\hline Adrenal Gland & 11.50 & 9.50 \\
\hline Kidney & 10.50 & 10.50 \\
\hline Pancreas & 10.50 & 10.50 \\
\hline Abdominal Wall & 900 & 12.00 \\
\hline
\end{tabular}

Berdasarkan hasil mean rank uji Mann Whitney pada tabel 5. Menunjukkan bahwa protokol tanpa Sure exposure memiliki nilai yang lebih tinggi dari pada protokol Sure exposure, terutama pada area anatomi Liver, Spleen dan Abdominal Wall.

Tabel 6. Hasil Dosis Radiasi pada Pemeriksaan CT

\begin{tabular}{ll}
\multicolumn{2}{c}{ Scam Abdomen } \\
\hline & DOSIS CTDIvou \\
\hline & $10.9 \mathrm{mGy}$ \\
& $13.7 \mathrm{mGy}$ \\
& $11.2 \mathrm{mGy}$ \\
& $15.4 \mathrm{mGy}$ \\
PROTOKOL SURE & $9.5 \mathrm{mGy}$ \\
EXPOSURE & $19.1 \mathrm{mGy}$ \\
& $14.5 \mathrm{mGy}$ \\
$10.8 \mathrm{mGy}$ \\
$17.7 \mathrm{mGy}$ \\
$12.2 \mathrm{mGy}$ \\
$\bar{X}=13.5 \mathrm{mGy}$ \\
\hline & $29.4 \mathrm{mGy}$ \\
$27.9 \mathrm{mGy}$ \\
$30.3 \mathrm{mGy}$ \\
PROTOKOL TANPA & $27.8 \mathrm{mGy}$ \\
& $31.7 \mathrm{mGy}$ \\
$33.9 \mathrm{mGy}$ \\
$28.0 \mathrm{mG}$ \\
$26.1 \mathrm{mGy}$ \\
$28.5 \mathrm{mGy}$ \\
$\bar{X}=29.24 \mathrm{mGy}$
\end{tabular}

Menurut Silvia (2013), dosis efektif pasien CT Scan bagian abdomen antara 7.72 - 19.38 mGy. Berdasarkan tabel 6 rata-rata CTDI pada pemeriksaan CT Scan Abdomen dengan penggunaan protokol sure exposure adalah 13.5 mGy yang berarti masih dalam rentang yang aman. Sedangkan rata-rata CTDI pada pemeriksaan CT Scan Abdomen dengan penggunaan protokol tanpa sure exposure adalah $29.24 \mathrm{mGy}$ yang berarti telah melewati batas aman pada dosis efektif CT Scan bagian abdomen.

\section{Perbedaan informasi anatomi CT Scan Abdomen pada penggunaan protokol Sure} Exposure dan Tanpa Sure Exposure

Pada penelitian mengenai perbedaan informasi anatomi pada pemeriksaan CT Scan Abdomen dilakukan pemeriksaan dengan protokol sure exposure dan tanpa sure exposure, berikut adalah hasil dari penilaian kuesioner responden:

a. Liver

Pemeriksaan CT Scan Abdomen dengan protokol sure exposure, pada organ liver masih dapat dilihat namun informasi citranya tidak jelas dikarenakan terdapat noise. Sedangkan pada penggunaan protokol tanpa sure exposure, organ liver dapat dengan mudah dilihat sehingga anatomi citra sangat jelas, terang dan tegas. Seperti gambar 2.
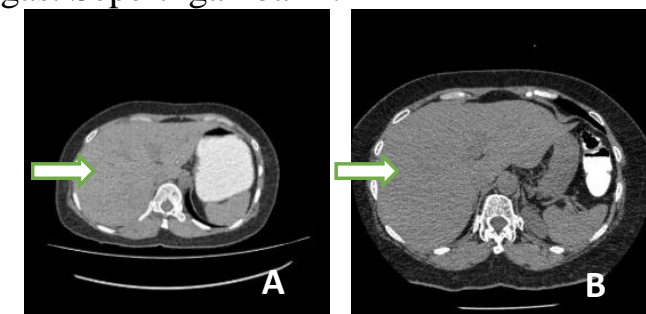

Gambar 2. Citra CT Scan Abdomen Organ Liver Protokol Sure Exposure (A) Tanpa Sure Exposure (B)

b. Spleen

Pada pemeriksaan CT Scan Abdomen dengan protokol sure exposure, pada organ spleen dapat dilihat dengan jelas dan batas antar organ tegas sehingga informasi citranya jelas. Pada penggunaan protokol tanpa sure exposure, organ spleen dapat dilihat dengan mudah sehingga informasi anatomi citra jelas, terang dan batas antar organ tegas. Seperti gambar 3.
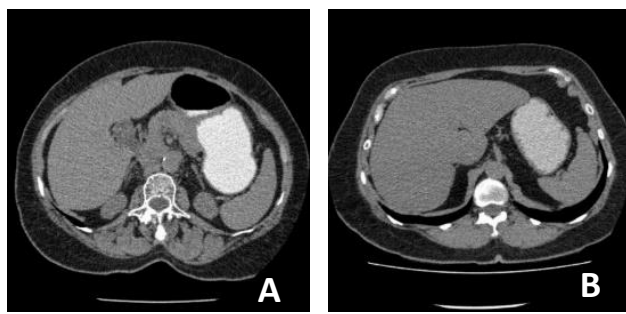
Gambar 3. Citra CT Scan Abdomen Organ Spleen Protokol Sure Exposure (A) Tanpa Sure Exposure

(B)

\section{c. Adrenal Gland}

Pada pemeriksaan CT Scan Abdomen dengan protokol sure exposure, pada organ adrenal gland dapat dilihat dengan jelas dan batas antar organ tegas sehingga informasi citranya jelas. Pada penggunaan protokol tanpa sure exposure, organ adrenal gland dapat dilihat dengan mudah sehingga informasi anatomi citra jelas, terang dan batas antar organ tegas. Seperti gambar 4.
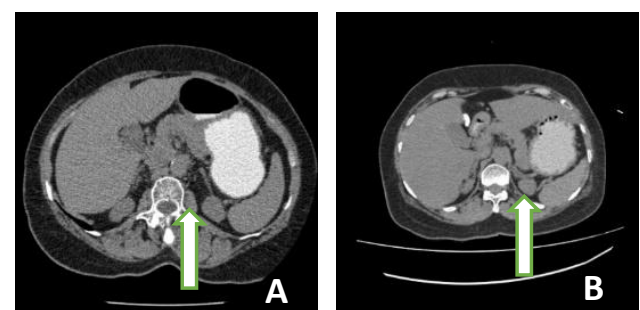

Gambar 4. Citra CT Scan Abdomen Organ Adrenal Gland Protokol Sure Exposure (A) Tanpa Sure Exposure (B)

\section{d. Kidney}

Pada pemeriksaan CT Scan Abdomen dengan protokol sure exposure, pada organ kidney dapat dilihat dengan jelas namun batas antar organ kurang tegas sehingga informasi anatomi citranya kurang jelas. Pada penggunaan protokol tanpa sure exposure, organ kidney dapat dilihat dengan mudah sehingga informasi anatomi citra jelas, terang dan batas antar organ tegas. Seperti gambar 5
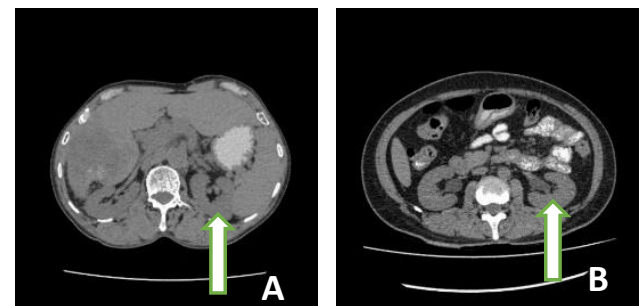

Gambar 5. Citra CT Scan Abdomen Organ Kidney

Protokol Sure Exposure (A) Tanpa Sure Exposure (B)

e. Pancreas

Pada pemeriksaan CT Scan Abdomen dengan protokol sure exposure, pada organ pancreas dapat dilihat dengan jelas dan batas antar organ cukup tegas sehingga informasi anatomi citranya cukup jelas. Pada penggunaan protokol tanpa sure exposure, organ pancreas dapat dilihat dengan mudah sehingga informasi anatomi citra jelas, terang dan batas antar organ tegas. Seperti gambar 6
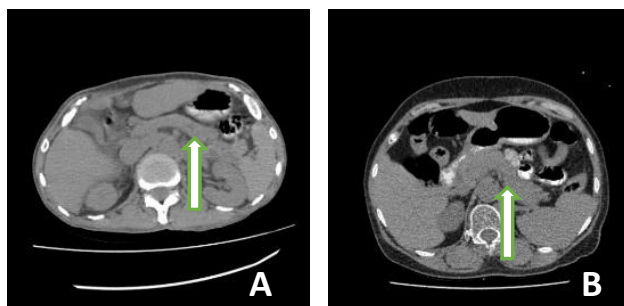

Gambar 6. Citra CT Scan Abdomen Organ Pancreas

Protokol Sure Exposure (A) Tanpa Sure Exposure

(B)

f. Abdominal Wall

Pada pemeriksaan CT Scan Abdomen dengan protokol sure exposure, pada organ abdominal wall dapat dilihat dengan jelas dan batas antar organ kurang tegas sehingga informasi anatomi citranya cukup jelas. Pada penggunaan protokol tanpa sure exposure, organ abdomial wall dapat dilihat dengan mudah sehingga informasi anatomi citra jelas, terang dan batas antar organ tegas. Seperti gambar 7 .
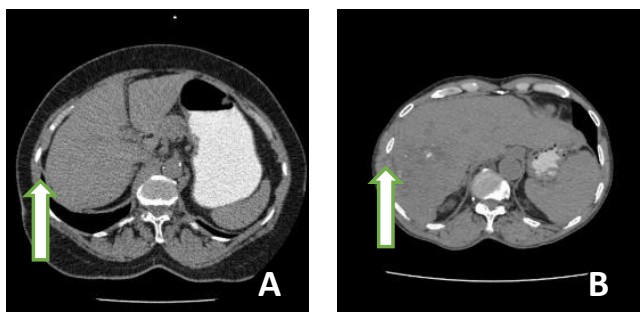

Gambar 7. Citra CT Scan Abdomen Organ

Abdominal Wall Protokol Sure Exposure (A) Tanpa Sure Exposure (B)

Berdasarkan hasil uji Mann Whitney U Test pada tabel 4, dapat diketahui bahwa kejelasan informasi anatomi tidak adanya perbedaan signifikan antara penggunaan protokol sure exposure dan tanpa sure exposure terhadap informasi anatomi Liver, Spleen, Adrenal Gland, Kidney, Pancreas dan Abdominal Wall.

Menurut penelitian Kalra (2002) mengenai efek kualitas citra terhadap penggunaan mAs standard dan $50 \%$ mAs menyatakan bahwa tidak adanya perbedaan yang signifikan antara penggunaan mAs standar dengan $50 \%$ mAs.

Berdasarkan hal tersebut, hasil penelitian penulis sejalan dengan teori dan penelitian terdahulu yang dilakukan oleh Kalra pada tahun (2002). Penelitian penulis pada perbedaan informasi anatomi pada penggunaan protokol sure exposure dan tanpa sure exposure pada pemeriksaan CT Scan Abdomen menyatakan tidak 
adanya perbedaan yang signifikan antara penggunaan protokol sure exposure dan tanpa sure exposure.

Tidak adanya perbedaan yang signifikan antara penggunaan kedua protokol tersebut, dikarenakan pada penggunaan protokol sure exposure mAs yang dikeluarka oleh pesawat sesuai dengan kebutuhan pasien untuk menghasilkan kualitas citra yang baik. Besar kecilnya mAs pada penggunaan protokol sure exposure menyesuaikan dengan ketebalan tubuh pasien. Sedangkan pada penggunaan tanpa sure exposure mAs yang digunakan yaitu 300 mAs. Dengan 300 mAs, pada pemeriksaan CT Scan Abdomen akan menghasilkan kualitas yang baik, karena semakin tinggi nilai $\mathrm{mAs}$ akan menambah intensitas sinar- $\mathrm{x}$ sehingga citra yang dihasilkan akan semakin baik.

Protokol yang lebih baik dalam menghasilkan informasi anatomi pada pemeriksaan CT Scan Abdomen antara penggunaan protokol sure exposure dan tanpa sure exposure

Berdasarkan hasil mean rank pada uji Mann Whitney pada tabel 5, menunjukkan bahwa pada organ Liver protokol tanpa sure lebih baik menghasilkan informasi anatomi daripada protokol sure exposure. Pada organ Spleen protokol tanpa sure exposure lebih baik menghasilkan informasi anatomi daripada protokol sure exposure. Pada organ Adrenal gland protokol sure exposure lebih baik menghasilkan informasi anatomi daripada protokol tanpa sure exposure. Pada organ Kidney protokol sure exposure lebih baik menghasilkan informasi anatomi daripada tanpa sure exposure. Pada organ Pancreas protokol tanpa sure exposure lebih baik menghasilkan informasi anatomi daripada protokol sure exposure. Sedangkan pada organ Abdominal wall protokol sure exposure lebih baik menghasilkan informasi anatomi daripada protokol tanpa sure exposure.

Berdasarkan hasil penelitian yang telah dilakukan, mengenai kejelasan informasi anatomi antara penggunaan protokol sure exposure dan tanpa sure exposure pada pemeriksaan CT Scan Abdomen, diketahui bahwa penggunaan protokol sure exposure tidak secara signifikan menghasilkan perbedaan kejelasan informasi anatomi dibandingkan pada penggunaan protokol tanpa sure exposure.

Responden pada penelitian ini juga menyatakan bahwa antara kedua citra masing-masing secara keseluruhan tidak terdapat perbedaan secara signifikan dari segi kejelasan anatomis yang meliputi Liver, Spleen, Adrenal gland, Kidney, Pancreas dan Abdominal wall.
Namun dari hasil dosis radiasi yang diterima pasien antara penggunaan protokol sure exposure dan tanpa sure exposure pada pemeriksaan CT Scan Abdomen sangat berbeda. Dosis protokol sure exposure adalah 13,5 mGy dan tanpa sure exposure 29,24 mGy.

Pada penggunaan protokol sure exposure dosis yang diterima pasien lebih rendah dibandingkan dengan penggunaan protokol tanpa sure exposure. Namun keduanya mendapatkan hasil kualitas citra yang tidak berbeda secara signifikan, dikarenakan pada penggunaan protokol sure exposure mAs yang diberikan sesuai dengan ketebalan pasien, penurunan arus tabung (mAs) juga akan menurunkan dosis radiasi yang diterima pasien.

Untuk itu penggunaan protokol sure exposure maupun tanpa sure exposure sebaiknya mempertimbangkan kasus yang ada, sehingga kualitas citra yang dihasilkanpun dapat lebih maksimal.

\section{Simpulan}

Berdasarkan analisis hasil kuesioner responden kejelasan informasi anatomi pada pemeriksaan CT Scan Abdomen pada organ liver, spleen dan abdominal wall informasi anatomi pada penggunaan protokol tanpa sure exposure lebih jelas, batas antar organ lebih tegas namun dengan penggunaan protokol sure exposurepun masih dapat dilihat, hanya batas antar organnya kurang tegas. Pada organ adrenal gland penggunaan protokol sure exposure lebih jelas menghasilkan informasi anatomi dengan batas antar organ yang lebih tegas daripada penggunaan protokol tanpa sure exposure, walaupun dengan penggunaan tanpa sure exposure masih dapat menghasilkan informasi anatomi yang baik. Sedangkan pada organ kidney dan pancreas penggunaan protokol sure exposure dan tanpa sure exposure akan menghasilkan kejelasan informasi anatomi dengan sangat jelas, terang serta batas antar organnya tegas.

Secara keseluruhan menunjukkan tidak terdapat perbedaan signifikan dan didukung dengan uji statistik yang menghasilkan nilai $p$ value $>0.05$ yaitu 0.549 yang artinya Ho diterima dan $\mathrm{Ha}$ ditolak.

Penggunaan protokol sure exposure akan lebih baik menghasilkan kejelasan informasi anatomi pada organ adrenal gland, kidney dan pancreas. Sedangkan penggunaan protokol tanpa sure exposure lebih baik menghasilkan informasi anatomi pada organ liver, spleen, adrenal gland, kidney, pancreas, dan abdominal wall. Secara keseluruhan penggunaan protokol tanpa sure 
exposure lebih baik dalam menghasilkan informasi anatomi pada pemeriksaan CT Scan Abdomen.

\section{Daftar Pustaka}

Angel, Erin. Sure Exposure Low Dose Diagnostic Image Quality. Toshiba America Medical System. 2012.

Choy, Taylor MD. Computed Tomography Abdomen/Pelvis in the Emergency Department: Can Clinical Parameter Guide the Appropriate Use of Imaging. Hawa'i Journal of Medicine \& Public Health. 2013.

Kalra, MK.. Automatic Exposure Control in Multidetector-row CT. Springer. 2011.

Maldjian, PD., dan Goldman, AR.. Reduction Radiation Dose in Body CT: A Primer on Dose Metrics and Key CT Technical Parameters. American Journal of Roentgenology. 2013.

Philips, C.Douglas. 2016, Acr-Asnr-Spr Practice Parameter For The Performance Of Computed Tomography (Ct) Of The Extracranial Head And Neck. United States. 2016.

Resmana, Tito Aditya. Perbedaan Image Noise dan Nilai Dosis Radiasi Penggunaan Piranti Aplikasi Care Dose 4D dan Non Care Dose 4D pada Pesawat MSCT Siemens. Jurnal Imejing Diagnostik Vol 3 No 2 Hal 231-276. Jurusan Teknik Radiodiagnostik dan Radioterapi. Poltekkes Kemenkes Semarang. 2017.

Singh, S., Kalra MK., Thrall, JH., Mahesh, M.. Automatic Exposure Control in CT: Application and Limitations. The Medical Physics Consult. 2011.

Seeram, Euclid, RT. Computed Tomograpy, Physical Prinsiples, Clinical Applications, and Quality Control. Saunders, Elsevier, USA. 2009.

Silvia, Helga. Estimasi Nilai CTDI dan Dosis Efektif Pasien Bagian Head, Thorax dan Abdomen Hasil Pemeriksaan CT Scan Merk Philips Briliance 6. Universitas Andalas Padang. 2013.

Siva, Raman P. CT Dose Reduction Application : Available Tools on the Latest Generatiom of CT Scanners. American Collage of Radiology. 2013. 